\title{
Análise de trilha de componentes de produção primários e secundários em tomateiro do grupo Salada
}

\author{
Gabriel Belfort Rodrigues(1), Bruno Garcia Marim(1), Derly José Henriques da Silva(1), \\ André Pugnal Mattedi ${ }^{(1)}$ e Victor de Souza Almeida ${ }^{(1)}$ \\ ${ }^{(1)}$ Universidade Federal de Viçosa, Avenida P.H. Rolfs, s/no, Campus Universitário, CEP 36570-000 Viçosa, MG. E-mail: gabelfor@yahoo.com, \\ bgmarim@yahoo.com.br, derly@ufv.br, andremattedi@yahoo.com.br, victoragroufv@yahoo.com.br
}

\begin{abstract}
Resumo - O objetivo deste trabalho foi avaliar as correlações genotípicas e seus desdobramentos em efeitos diretos e indiretos de componentes de produção primários e secundários sobre a produtividade de frutos em acessos de tomateiro, pela análise de trilha. Foram utilizados dados de 20 características, avaliadas em 132 acessos de tomateiro do grupo Salada, do Banco de Germoplasma de Hortaliças da Universidade Federal de Viçosa. Após o diagnóstico de multicolinearidade, oito características foram descartadas, e a análise de trilha foi realizada com: variável principal (produção total de frutos); variáveis primárias (peso médio e número total de frutos); e variáveis secundárias (frutos não comercializáveis, índice de precocidade, comprimento da folha, espessura do pecíolo principal, comprimento e diâmetro do entrenó, número de lóculos, acidez total e sólidos solúveis totais dos frutos). O comprimento da folha, o índice de precocidade e o diâmetro do entrenó apresentaram maior correlação genotípica com a produção total de frutos $(0,69 ;-0,54$ e 0,5 , respectivamente). A análise de trilha com um único diagrama causal mostrou igual importância das variáveis primárias na determinação da produção. A análise de trilha com dois diagramas causais mostrou que a seleção simultânea do comprimento da folha e do diâmetro do entrenó pode ser uma boa alternativa para a obtenção de ganhos na produção total de frutos.
\end{abstract}

Termos para indexação: Lycopersicon esculentum, correlação genotípica, eficiência da seleção, melhoramento.

\section{Path analysis of primary and secondary yield components in tomato plants of the Salad group}

\begin{abstract}
The objective of this work was to evaluate the genotypic correlations and their development in direct and indirect effects of primary and secondary yield components on the fruit production of tomato accessions of the Salad group using path analysis. Data of 20 characters of 132 tomato accessions of the Salad group from the Germplasm Bank of Universidade Federal de Viçosa were used. After multicollinearity diagnosis, eight characters were discarded, and the path analysis was carried out with: main variable (total fruit yield); primary variables (average fruit weight and total number of fruits); and secondary variables (non-commercial fruits, precocity index, leaf length, thickness of main petiole, stem internode length and diameter, number of locules, total acidity and total soluble solids of the fruits). Leaf length, precocity index and stem internode diameter were the characters with highest genotypic correlation with total fruit yield. The path analysis with only one causal diagram showed equal importance of the primary variables in determining the yield $(0.69,-0.54,0.5$, respectively). The path analysis with two causal diagrams showed that the simultaneous selection of leaf length and stem internode diameter can be a good alternative for obtaining gains in the total fruit yield.
\end{abstract}

Index terms: Lycopersicon esculentum, genetic correlation, efficiency of selection, breeding.

\section{Introdução}

Em 1964, a Universidade Federal de Viçosa (UFV) iniciou as coletas de ecótipos de hortaliças junto a agricultores para a formação do Banco de Germoplasma de Hortaliças (Silva et al., 2001). A primeira coleção do Banco de Germoplasma de Hortaliças da UFV, com trabalhos contínuos de caracterização, foi a de tomate, em razão da sua importância econômica e alimentar. Já foram caracterizados mais de 300 acessos de tomateiro utilizando-se descritores recomendados pelo International Plant Genetic Resource Institute (1996), tendo sido verificada grande variabilidade quanto a características agronômicas, morfológicas e de qualidade de fruto (Marim et al., 2009). Mais da metade dos acessos pertencem ao grupo comercial 
Salada (Marim, 2007). Esse grupo é o mais produzido no Brasil, e o responsável pelo aumento em produtividade e pela redução das perdas na tomaticultura de mesa na última década (Informativo Conjuntural, 2006).

Entre outras finalidades, a caracterização de acessos de tomateiro possibilita o estudo do grau de associação entre os caracteres. As correlações entre os caracteres podem ser utilizadas para melhoramento, principalmente na seleção de características de baixa herdabilidade, como a produção (Cruz et al., 2004), uma das características de maior interesse para os melhoristas e que tem contribuído para a modernização e expansão da tomaticultura no mundo (Sedyama et al., 2003).

Apesar da utilidade da correlação genotípica no entendimento de um caráter complexo como a produção, ela não determina a importância dos efeitos diretos e indiretos dos caracteres que a compõem (Furtado et al., 2002). Assim, não é possível constatar se a sua estimativa foi estabelecida por verdadeiras relações de causa e efeito (Carvalho et al., 1999).

Com essa finalidade, Wright (1921) propôs a análise de trilha que permite, por meio da padronização das variáveis e equações de regressão, estimar os efeitos diretos e indiretos das características explicativas sobre uma característica principal (Carvalho et al., 1999; Coimbra et al., 1999; Furtado et al., 2002).

$\mathrm{Na}$ literatura, existem trabalhos que avaliaram a correlação genotípica de muitas características com a produção do tomateiro e seus desdobramentos em efeitos diretos e indiretos (Cuartero \& Cubero, 1982; Markovic et al., 1997; Rani et al., 2008). No entanto, nenhum avaliou apenas genótipos do grupo comercial Salada.

O objetivo deste trabalho foi avaliar as correlações genotípicas de componentes de produção primários e secundários, e seus desdobramentos em efeitos diretos e indiretos, sobre a produtividade de frutos em acessos de tomateiro do grupo Salada, mediante análise de trilha.

\section{Material e Métodos}

Os experimentos foram realizados no campo experimental do Departamento de Fitotecnia da Universidade Federal de Viçosa (UFV), de 2002 a 2005. Foram realizados oito experimentos (dois por ano). Em média, 16 acessos distintos foram avaliados em cada ensaio, o que totalizou 132 acessos de tomate do grupo comercial Salada, do Banco de Germoplasma de Hortaliças da UFV. As cultivares Débora Plus e Santa Clara foram utilizadas como testemunhas comuns.

Os acessos foram semeados em bandejas de 128 células. O transplantio para o campo foi realizado quando as mudas tinham, em média, quatro folhas definitivas. O solo foi arado, gradeado e corrigido, e a adubação foi realizada no sulco de plantio e em sete coberturas.

No sulco de plantio, foram aplicados $40 \mathrm{Mg} \mathrm{ha}^{-1}$ de esterco de boi, $10 \mathrm{~kg} \mathrm{ha}^{-1}$ de bórax, $10 \mathrm{~kg} \mathrm{ha}^{-1}$ de sulfato de zinco, $200 \mathrm{~kg} \mathrm{ha}^{-1}$ de sulfato de magnésio e $16 \mathrm{~kg} \mathrm{ha}^{-1}$ de $\mathrm{N}, 400 \mathrm{~kg} \mathrm{ha}^{-1}$ de $\mathrm{P}_{2} \mathrm{O}_{5}$ e $20 \mathrm{~kg} \mathrm{ha}^{-1}$ de $_{2} \mathrm{O}$ na forma de sulfato de amônia, superfosfato simples e cloreto de potássio, respectivamente. As adubações de cobertura foram realizadas aos $15,30,45,60,75,90$ e 105 dias após o transplantio, por meio de fertirrigação. Essas adubações foram diferenciadas: na primeira e na segunda, foram aplicados $30,4 \mathrm{~kg} \mathrm{ha}^{-1}$ de $\mathrm{N}$ e $18 \mathrm{~kg} \mathrm{ha}^{-1}$ de $\mathrm{K}_{2} \mathrm{O}$; na terceira e na quarta adubações de cobertura, foram aplicados $45,6 \mathrm{~kg} \mathrm{ha}^{-1}$ de $\mathrm{N}$ e $27 \mathrm{~kg} \mathrm{ha}^{-1}$ de $\mathrm{K}_{2} \mathrm{O}$; na quinta e na sexta, $60,8 \mathrm{~kg} \mathrm{ha}^{-1}$ de $\mathrm{N}$ e $36 \mathrm{~kg} \mathrm{ha}^{-1} \mathrm{de}$ $\mathrm{K}_{2} \mathrm{O}$; e por fim, na sétima adubação de cobertura, foram aplicados $30,4 \mathrm{~kg} \mathrm{ha}^{-1}$ de $\mathrm{N}$ e $18 \mathrm{~kg} \mathrm{ha}^{-1}$ de $\mathrm{K}_{2} \mathrm{O}$.

As plantas foram tutoradas pelo método vertical com fitilho e conduzidas com uma haste e seis racimos, em espaçamento de $0,6 \times 1,1 \mathrm{~m}$. A irrigação foi realizada por gotejamento utilizando tubos com distância de 0,3 m entre os emissores. Os tratos culturais (desbrotas, tutoramento e capinas) e o controle fitossanitário foram realizados, sempre que necessário, utilizando defensivos recomendados para a cultura.

Foram avaliadas características vegetativas, de fruto, agronômicas e de qualidade dos frutos de acordo com as recomendações do International Plant Genetic Resources Institute (1996), com algumas adaptações.

Para as características vegetativas, foram realizadas duas medições por repetição, em plantas úteis distintas e escolhidas aleatoriamente, na folha ou entrenó imediatamente acima do terceiro cacho. Foram avaliados: comprimento da folha $(\mathrm{cm})$, medido da base da folha até a extremidade distal do último folíolo; largura da folha $(\mathrm{cm})$, medida no segundo par de folíolos; espessura do pecíolo principal (mm), medida no pecíolo principal, na posição mediana entre o segundo e o terceiro par de folíolos; comprimento do entrenó (mm) e diâmetro do entrenó ( $\mathrm{mm})$, medidos na posição mediana do entrenó. 
Para as características de fruto, foram realizadas seis medições por repetição, com dois frutos de cada planta útil da parcela colhidos do segundo ou do terceiro cacho. Foram avaliados: comprimento do fruto $(\mathrm{mm})$; largura do fruto $(\mathrm{mm})$; espessura do mesocarpo $(\mathrm{mm})$; espessura do endocarpo ( $\mathrm{mm}$ ); largura do eixo central (mm); número de lóculos. As características espessura do mesocarpo, espessura do endocarpo e largura do eixo central foram medidas após o corte na seção mediana dos frutos. Para todas as características de fruto, as medições foram tomadas na posição do fruto que resultava na maior medida.

As características agronômicas avaliados foram: produção total de frutos ( $\mathrm{g}$ planta $\left.{ }^{-1}\right)$; número total de frutos (frutos planta ${ }^{-1}$ ); peso médio dos frutos (g fruto ${ }^{-1}$ ), obtido pela razão entre as características produção total de frutos e o número total de frutos; frutos não comercializáveis (\%), obtido pela razão entre o número de frutos não comercializáveis e o número total de frutos, multiplicado por 100; índice de precocidade (\%), obtido pela razão entre a produção $\left(\mathrm{g} \mathrm{planta}^{-1}\right)$ das duas primeiras colheitas e a produção total de frutos, multiplicado por 100 . As colheitas foram realizadas semanalmente $\mathrm{e}$ simultaneamente para todos os acessos e testemunhas. Foram considerados como frutos não comercializáveis aqueles com defeitos causados por pragas, doenças, deficiências nutricionais. Frutos com rachaduras e lóculo aberto foram considerados bons, e essas características foram avaliadas separadamente.

As características de qualidade dos frutos foram obtidas a partir de medições realizadas em amostras de três frutos (um de cada planta útil) por parcela, acidez total $(\mathrm{pH})$, avaliada com auxílio de medidor de $\mathrm{pH}$ digital; sólidos solúveis totais ( $\left.{ }^{\circ} \mathrm{Brix}\right)$, medido com o auxílio de um refratômetro portátil; acidez total titulável (percentagem de ácido cítrico); qualidade organoléptica, obtida pela razão entre sólidos solúveis totais e acidez total titulável. Utilizaram-se frutos do segundo e do terceiro cacho para as medições de qualidade dos frutos.

Cada experimento foi conduzido em blocos ao acaso, com três repetições e seis plantas por parcela, e foram escolhidas aleatoriamente três plantas úteis. Realizou-se a análise de variância agrupada, de acordo com o esquema "1" ilustrado por Cruz \& Carneiro (2003), e foram obtidas as variâncias e covariâncias genotípicas para gerar a matriz de correlações genotípicas entre os caracteres. Essa matriz foi submetida aos testes de multicolinearidade segundo Montgomery \& Peck (1981).

Ao se detectar multicolinearidade, priorizouse o emprego da análise em crista, que permite a manutenção de todas as variáveis no modelo (Cruz $\&$ Carneiro, 2003). Nos casos em que houve a necessidade de se empregar valores de $\mathrm{k}$ próximos à unidade, optou-se pela exclusão das variáveis que estivessem contribuindo com a multicolinearidade. Com as variáveis restantes, empregou-se a análise de trilha sob os dados padronizados.

Primeiramente foi realizada a análise de trilha considerando-se um único diagrama causal, ou seja, a variável principal (produção total de frutos) em função de dois componentes primários (peso médio dos frutos e o número total de frutos). Posteriormente, realizou-se a análise de trilha considerando dois diagramas causais, ou seja, variável principal em função dos componentes primários e estas em função de componentes secundários. As características produção total de frutos, peso médio dos frutos e número total de frutos foram transformadas para a escala logarítmica devido à existência de inter-relação entre elas, em razão do efeito multiplicativo. Para todas as análises estatísticas foi utilizado o programa Genes versão 2007 (Cruz, 2001).

\section{Resultados e Discussão}

Algumas características apresentaram altas correlações genotípicas (maiores que 0,8 em módulo), como a observada, entre comprimento da folha e largura da folha $(0,895)$. Contudo, em relação à variável principal (produção total de frutos) não houve nenhuma característica altamente correlacionada. As maiores correlações em relação a essa característica foram com o comprimento da folha $(0,694)$, o índice de precocidade $(-0,544)$ e o diâmetro do entrenó $(0,500)$. Já os componentes primários da produção (peso médio dos frutos e número total de frutos) apresentaram valores de correlação genotípica com produção total de frutos de 0,380 e 0,428, respectivamente (Tabela 1). Esse resultado é inesperado, uma vez que a produção é o produto entre o número de frutos e o peso médio de frutos. No entanto, ele reforça o fato de que coeficientes de correlações simples não representam a relação exata de causa e efeito dos caracteres. Dessa forma, o 


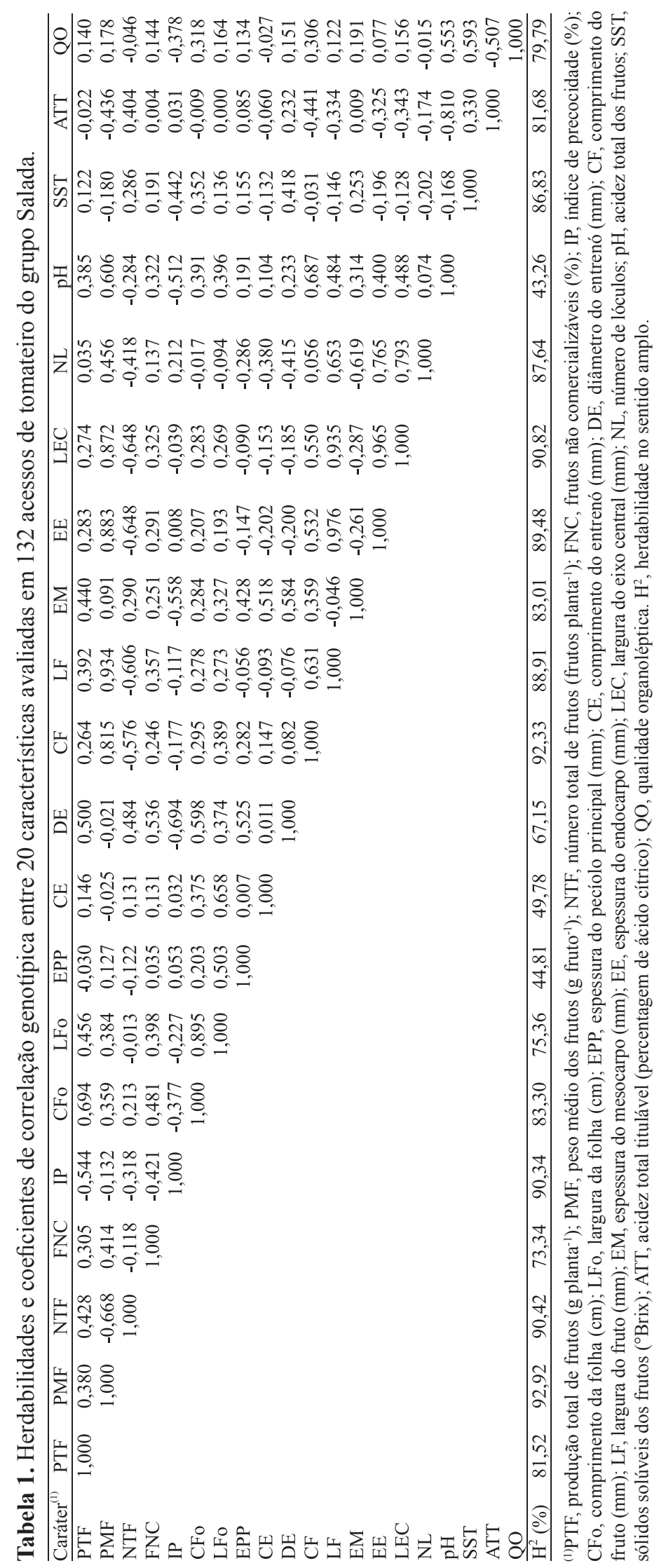


emprego da análise de trilha, proposta inicialmente por Wright (1921), é de grande utilidade.

Verificou-se que alguns caracteres contribuíram para a multicolinearidade de forma moderada a forte $(100<$ número de condição<1.000) ou severa (número de condição $>1.000$ ), de acordo com a classificação de Montgomery \& Peck (1981). Em presença de multicolinearidade, as variâncias associadas aos estimadores dos coeficientes de trilha podem atingir valores excessivamente altos, tornando-se pouco confiáveis. Além disso, as estimativas dos parâmetros podem assumir valores absurdos ou sem nenhuma coerência com o fenômeno biológico estudado (Carvalho et al., 1999; Cruz \& Carneiro, 2003).

Para resolver os problemas da multicolinearidade, realizou-se a análise em crista que, no entanto, não foi efetiva. Portanto, foram descartadas da análise de trilha as seguintes características: largura da folha, comprimento do fruto, largura do fruto, espessura do mesocarpo, espessura do endocarpo, largura do eixo central, número de frutos comercializáveis, produção de frutos comercializáveis, acidez total titulável e qualidade organoléptica.

Pela análise de trilha com um diagrama causal, verificou-se que os componentes primários (peso médio dos frutos e número total de frutos) tiveram altas magnitudes dos efeitos diretos e indiretos sobre a produção total de frutos. Os efeitos diretos foram maiores que a unidade: 1,201 , para o peso médio dos frutos, e 1,230, para o número total de frutos (Tabela 2). Isso é possível porque os coeficientes de trilha foram estimados com base em dados padronizados e, assim,

Tabela 2. Estimativas dos efeitos diretos e indiretos das variáveis primárias (peso médio e número total de frutos) sobre a variável principal (produção total de frutos), em acessos de tomateiro do grupo Salada.

\begin{tabular}{lc}
\hline Efeito & Estimativa \\
\hline \multicolumn{2}{c}{$\quad$ Peso médio dos frutos } \\
Direto sobre produção total de frutos & 1,201 \\
Indireto via número total de frutos & $-0,821$ \\
\hline \multicolumn{2}{c}{$\quad$ Número total de frutos } \\
\hline \multicolumn{2}{c}{0,380} \\
Direto sobre produção total de frutos \\
Indireto via peso médio dos frutos \\
\hline Total & 1,230 \\
$\mathrm{R}^{2(1)}$ & $-0,802$ \\
Efeito residual & 0,428 \\
\hline
\end{tabular}

${ }^{(1)} \mathrm{R}^{2}$, coeficiente de determinação do modelo de trilha com um único diagrama causal. foram obtidos do mesmo modo que os coeficientes de regressão. Os componentes de correlação podem atingir valores maiores que a unidade ou menores que -1 (Vencovsky \& Barriga, 1993).

Os efeitos indiretos do peso médio dos frutos via número total de frutos, e vice-versa, sobre a produção foram negativos (Tabela 2). Esse resultado deve-se à redução do peso por fruto com o aumento do número de frutos, sendo que o contrário também é verdadeiro. Resultados semelhantes foram obtidos por outros autores (Markovic et al., 1997; Rani et al., 2008).

As correlações genotípicas entre os componentes primários e a variável principal foram similares, assim como os efeitos diretos e os indiretos (Tabelas 1 e 2). Isso demonstra que o peso médio dos frutos e o número total de frutos são igualmente importantes na produção no tomateiro do grupo Salada. Rani et al. (2008) não verificaram essas similaridades, e encontraram maior importância do peso médio dos frutos na determinação da produção total de frutos. Porém, esses autores não trabalharam exclusivamente com genótipos do grupo Salada.

Segundo Coimbra et al. (2004), quando se observam efeitos diretos altos e positivos, bem como indiretos altos e negativos, a seleção indireta pode não proporcionar ganhos satisfatórios. Dessa forma, o emprego da seleção simultânea de caracteres é mais apropriado (Cruz et al., 2004), desde que as características apresentem valores de herdabilidades compatíveis (próximos), em comparação aos da variável principal.

Neste trabalho, as herdabilidades para peso médio dos frutos $(92,92 \%)$ e número total de frutos $(90,42 \%)$ foram maiores que para a produção total de frutos $(81,52 \%)$. Assim, é possível utilizar um índice de seleção para os dois componentes primários e obter ganhos sobre a variável principal (Tabela 1). Contudo, o peso médio dos frutos e o número total de frutos são de difícil aferição e demandam o mesmo número de avaliações que a produção total de frutos, o que torna pouco vantajosa a utilização desses índices, por não aumentar a capacidade de avaliação da população.

O emprego de técnicas que aumentam o ganho com a seleção e que possibilitam a avaliação de grande número de indivíduos é de suma importância no melhoramento de plantas, e a resposta correlacionada é uma delas (Cruz et al, 2004). Dessa forma, torna-se necessário o estudo dos efeitos diretos e indiretos de outras características avaliadas sobre a produção total de frutos. 
Como algumas características foram eliminadas devido a problemas com multicolinearidade, as variáveis secundárias consideradas na análise de trilha com dois diagramas causais foram: percentagem de frutos não comercializáveis, índice de precocidade, comprimento da folha, espessura do pecíolo principal, comprimento do entrenó, diâmetro do entrenó, número de lóculos, acidez total dos frutos e sólidos solúveis totais.

O comprimento da folha e o diâmetro do entrenó apresentaram os maiores valores de correlação genotípica e efeito direto com a produção total de frutos (Tabela 3). Além disso, o comprimento da folha apresentou razoável efeito indireto, via diâmetro do entrenó, sobre a produção total de frutos, e o contrário também foi verificado, ou seja, razoável efeito indireto do diâmetro do entrenó via comprimento da folha. Dessa forma, existe uma tendência para que plantas com folhas mais compridas e com entrenós com maior diâmetro produzam mais.

De fato, em sistemas sem limitação de água, folhas grandes possibilitam maior produção de fotoassimilados devido à maior área fotossintética, o que implica maior fotossíntese líquida às plantas na forma de produção de frutos (Taiz \& Zeiger, 2006). Além disso, plantas com maior diâmetro de entrenós têm o sistema vascular mais desenvolvido, o que permite melhor transporte de nutrientes e água para os frutos. Maior quantidade de água no fruto implica maior produção, já que $95 \%$ do fruto de tomate é composto por essa substância (Fontes \& Silva, 2005).

Como o comprimento da folha e o diâmetro do entrenó podem ser avaliados precocemente - terceira folha ou entrenó acima do terceiro racimo, quando os primeiros frutos estiverem fisiologicamente maduros -, eles são de fácil avaliação (uma única avaliação) e apresentaram herdabilidade de 83,31 e $67,15 \%$, respectivamente. Utilizar um índice de seleção para essas características pode ser uma boa alternativa para a obtenção de ganhos na produção total de frutos (Tabela 1).

Uma vez que as variáveis primárias são difíceis de avaliar e não é muito eficiente utilizá-las diretamente para a obtenção de ganhos na produção total de frutos, o estudo dos efeitos diretos e indiretos das variáveis secundárias sobre o peso médio dos frutos e o número total de frutos é justificado.

Ao se analisar os efeitos diretos e indiretos das variáveis secundárias sobre o peso médio de frutos, verificou-se que a acidez total dos frutos apresentou coeficiente de correlação genética total e efeito direto altos $(0,606$ e 0,965 , respectivamente $)$ sobre essa variável (Tabela 3). Segundo Causse et al. (2004), os ácidos málico e cítrico são os principais ácidos orgânicos que compõem o tomate e, em altas concentrações nas fases iniciais do desenvolvimento do fruto, tornam a parede celular mais permeável à água, aumentando o tamanho do fruto e o $\mathrm{pH}$. No entanto, a herdabilidade para acidez total dos frutos foi aproximadamente a metade da herdabilidade para o seu peso médio (Tabela 1). Nessas condições, o emprego da seleção indireta não aumentaria a eficiência do melhoramento.

O número de lóculos com valores de correlação e efeito direto de 0,486 e 0,456 , respectivamente, sobre o peso médio dos frutos (Tabela 3 ) corroboram os resultados de outros autores e destacam a importância do número de lóculos na determinação do tamanho dos frutos (Lippman \& Tanksley, 2001; Barrero \& Tanksley, 2004).

A herdabilidade para o número de lóculos $(87,69 \%)$ foi ligeiramente menor do que a herdabilidade para o peso médio de fruto $(92,92 \%)$ (Tabela 1$)$. Contudo, a facilidade e a precocidade de avaliação do número de lóculos (os frutos podem ser avaliados ainda verdes) tornam seu emprego próprio à seleção indireta e bastante vantajoso, principalmente pelo aumento da capacidade de avaliação de indivíduos da população.

Ao se analisarem os efeitos diretos e indiretos das variáveis secundárias sobre o número total de frutos, não se verificou nenhuma relação de causa e efeito. $\mathrm{O}$ que se observou foram caracteres relacionados ao número total de frutos pelos efeitos direto ou indireto, como índice de precocidade, comprimento da folha, diâmetro do entrenó, acidez total de frutos e sólidos solúveis totais (Tabela 3), o que demonstra a necessidade de construção de índices de seleção que considerem todos esses caracteres, simultaneamente, para se obter o adequado número de frutos. No entanto, esse tipo de procedimento seria bastante complicado e, mesmo que possível, não facilitaria a avaliação dos indivíduos da população a ser melhorada. 


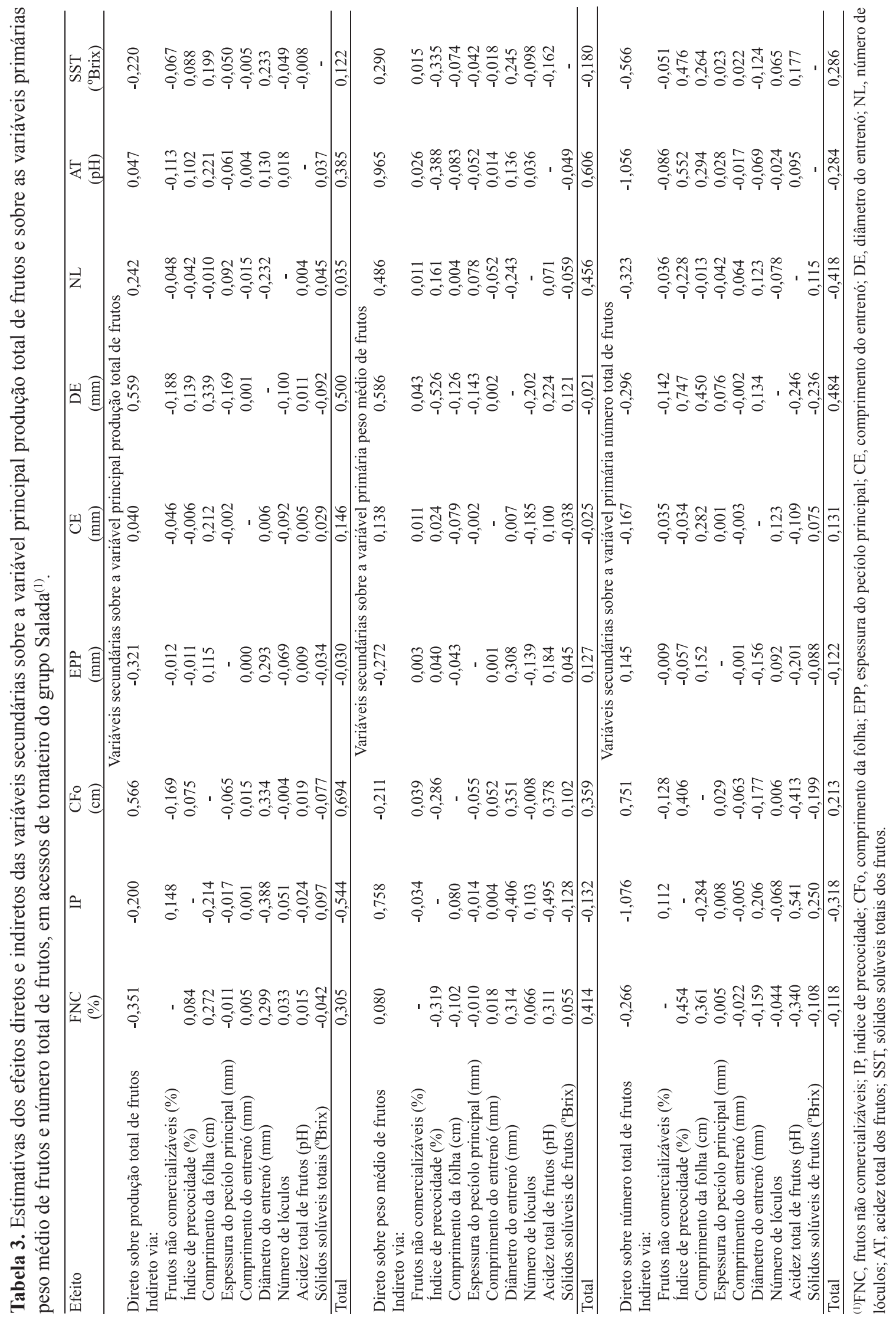




\section{Conclusões}

1. Os componentes primários da produção peso médio dos frutos e número total de frutos têm igual importância na determinação da produção total de frutos do tomateiro do grupo Salada.

2. A seleção simultânea do comprimento da folha e do diâmetro do entrenó pode ser uma boa alternativa para a obtenção de ganhos na produção total de frutos.

3. Para o peso médio dos frutos, é possível obter ganhos via seleção indireta utilizando a característica número de lóculos.

4. Para o número total de frutos, não existe nenhuma característica ou grupo de características que permita ganhos via resposta correlacionada.

\section{Agradecimentos}

Ao Conselho Nacional de Desenvolvimento Científico e Tecnológico e à Fundação de Amparo à Pesquisa do Estado de Minas Gerais, pela concessão de bolsas e pelo apoio financeiro.

\section{Referências}

BARRERO, L.S.; TANKSLEY, S.D. Evaluating the genetic basis of multiple-locule fruit in a broad cross section of tomato cultivars. Theoretical and Applied Genetics, v.109, p.669-679, 2004.

CARVALHO, C.G.P.; OLIVEIRA, V.R.; CRUZ, C.D.; CASALI, W.D. Análise de trilha sob multicolinearidade em pimentão. Pesquisa Agropecuária Brasileira, v.34, p.603-613, 1999.

CAUSSE, M.; DUFFE, P.; GOMEZ, M.C.; BURET, M.; DAMIDAUX, R.; ZAMIR, D.; GUR, A.; CHEVALIER, C.; LEMAIRE-CHAMLEY, M.; ROTHAN, C. A genetic map of candidate genes and QTLs involved in tomato fruit size and composition. Journal of Experimental Botany, v.55, p.1671-1685, 2004.

COIMBRA, J.L.M.; GUIDOLIN, A.F.; ALMEIDA, M.L.; SANGOI, L.; ENDER, M.; MEROTTO JÚNIOR, A. Análise de trilha dos componentes do rendimento de grãos em genótipos de canola. Ciência Rural, v.34, p.1421-1428, 2004.

COIMBRA, J.L.M.; GUIDOLIN, A.F.; CARVALHO, F.I.F. Análise de trilha I: análise do rendimento de grãos e seus componentes. Ciência Rural, v.29, p.213-218, 1999.

CRUZ, C.D. Programa GENES: versão Windows; aplicativo computacional em genética e estatística. Viçosa: UFV, 2001. 442p.

CRUZ, C.D.; CARNEIRO, P.C.S. Modelos biométricos aplicados ao melhoramento genético II. Viçosa: UFV, 2003. 585p.

CRUZ, C.D.; REGAZZI, A.J.; CARNEIRO, P.C.S. Modelos biométricos aplicados ao melhoramento genético I. Viçosa: UFV, 2004. 480p.
CUARTERO, J.; CUBERO, J.I. Phenotypic, genotypic and environmental correlation in tomato (Lycopersicon esculentum). Euphytica, v.31, p.151-159, 1982.

FONTES, P.C.R.; SILVA, D.J.H.S. Cultura do tomate. In: FONTES, P.C.R. (Ed.). Olericultura teoria e prática. Viçosa: UFV, 2005. p.457-475.

FURTADO, M.C.; CRUZ, C.D.; CARDOSO,A.A.; COELHO,A.D.F.; PETERNELLI, L.A. Análise de trilha do rendimento do feijoeiro e seus componentes primários em monocultivo e em consórcio com a cultura do milho. Ciência Rural, v.32, p.217-220, 2002.

INFORMATIVO CONJUNTURAL. Belo Horizonte: SEAPA/ Centro de Análises e Estudos Estratégicos, n.18, 2006. 29p. Disponível em: <http://www.agricultura.mg.gov.br/files/conjuntura/ conjuntura_09_2006.pdf>.Acesso em: 21 fev. 2009.

INTERNATIONAL PLANT GENETIC RESOURCES INSTITUTE. Descriptors for tomato (Lycopersicon spp.). Roma: International Plant Genetic Resources Institute, 1996. 56p.

LIPPMAN, Z.; TANKSLEY, S. Dissecting the genetic pathway to extreme fruit size in tomato using a cross between the smallfruited wild species Lycopersicon pimpinellifolium and L. esculentum var. Giant Heirloom. Genetics, v.158, p.413-422, 2001.

MARIM, B.G. Diversidade genética e subcoleção representativa dos acessos de tomateiro do Banco de Germoplasma de Hortaliças da Universidade Federal de Viçosa. 2007. 53p. Dissertação (Mestrado) - Universidade Federal de Viçosa, Viçosa.

MARIM, B.G.; SILVA, D.J.H.; CARNEIRO, P.C.S.; MIRANDA, G.V.; MATTEDI, A.P.; CALIMAN, F.R.B. Variabilidade genética e importância relativa de caracteres em acessos de germoplasma de tomateiro. Pesquisa Agropecuária Brasileira, v.44, p.1283-1290, 2009.

MARKOVIC, Z.; ZDRAVKOVIC, J.; DAMJANOVIC, M. Correlation between the morphological characteristics and the biochemical components of tomato fruit quality. Acta Horticulturae, v.462, p.151-156, 1997.

MONTGOMERY, D.C.; PECK, E.A. Introduction to linear regression analysis. New York: John Wiley, 1981. 504p.

RANI, C.I.; VEERARAGAVATHATHAM, D.; SANJUTHA, S. Studies on correlation and path coefficient analysis on yield attributes in root knot nematode resistant F1 hybrids of tomato. Journal of Applied Sciences Research, v.4, p.287-295, 2008.

SEDIYAMA, M.A.N.; FONTES, P.C.R.; SILVA, D.J.H. Práticas culturais adequadas ao tomateiro. Informe Agropecuário, v.24, p.19-25, 2003.

SILVA, D.J.H.; MOURA, M.C.; CASALI, V.W.D. Recursos genéticos do banco de germoplasma de hortaliças da UFV: histórico e expedições de coleta. Horticultura Brasileira, v.19, p.108-114, 2001.

TAIZ, L.; ZEIGER, E. Plant Physiology. Sunderland: Sinauer, 2006. 705p.

VENCOVSKY, R.; BARRIGA, P. Genética biométrica no fitomelhoramento. Ribeirão Preto: Sociedade Brasileira de Genética, 1993. 496p.

WRIGHT, S. Correlation and causation. Journal of Agricultural Research, v.20, p.557-585, 1921.

Recebido em 17 de março de 2009 e aprovado em 29 de janeiro de 2010

Pesq. agropec. bras., Brasília, v.45, n.2, p.155-162, fev. 2010 